\title{
The relationship between Plasmodium infection, anaemia and nutritional status in asymptomatic children aged under five years living in stable transmission zones in Kinshasa, Democratic Republic of Congo
}

Vivi Maketa ${ }^{1,2^{*}}$, Hypolite Muhindo Mavoko ${ }^{1,2}$, Raquel Inocêncio da Luz², Josué Zanga ${ }^{1}$, Joachim Lubiba ${ }^{3}$, Albert Kalonji ${ }^{3}$, Pascal Lutumba ${ }^{1}$ and Jean-Pierre Van geertruyden ${ }^{2}$

\begin{abstract}
Background: Malaria is preventable and treatable when recommended interventions are properly implemented. Thus, diagnosis and treatment focus on symptomatic individuals while asymptomatic Plasmodium infection (PI) plays a role in the sustainability of the transmission and may also have an impact on the morbidity of the disease in terms of anaemia, nutritional status and even cognitive development of children. The objective of this study was to assess PI prevalence and its relationship with known morbidity factors in a vulnerable but asymptomatic stratum of the population.

Methods: A simple random sample, household survey in asymptomatic children under the age of five was conducted from April to September 2012 in two health areas of the health zone of Mont Ngafula 1, Kinshasa, Democratic Republic of Congo.

Results: The PI prevalence were 30.9\% (95\% Cl: 26.5-35.9) and 14.3\% (95\% Cl: 10.5-18.1) in Cité Pumbu and Kindele health areas, respectively, (OR: 2.7; $\mathrm{p}<0.001)$. All were Plasmodium falciparum infected and $4 \%$ were co-infected with Plasmodium malariae. In Cité Pumbu and Kindele, the prevalence of anaemia (haemoglobin $<11 \mathrm{~g} / \mathrm{dL}$ ) was 61.6\% (95\% Cl: $56.6-66.5$ ) and 39.3\% (95\% Cl: 34.0-44.6), respectively, (OR: $2.5 ; \mathrm{p}<0.001)$. The health area of Cité Pumbu had 32\% (95\% Cl: 27.5-37.0) of chronic malnutrition (HAZ score $\leq-2 \mathrm{SD}$ ) compared to 5.1\% (95\% Cl: 2.8-7.6) in Kindele. PI was predictor factor for anaemia (aOR: $3.5, p=0.01$ ) and within infected children, there was an inverse relationship between parasite density and haemoglobin level $\left(\beta=-5^{*} 10^{-5}, p<0.001\right)$. Age older than 12 months (aOR: $3.8, p=0.01$ ), presence of anaemia (aOR: $3.4, p=0.001$ ), chronic malnutrition (aOR: 1.8, $p=0.01$ ), having a single parent/guardian (aOR: 1.6, $p=0.04$ ), and the non-use of insecticide-treated nets (aOR: 1.7, $p=0.04$ ) were all predictors for $\mathrm{PI}$ in the overall population.
\end{abstract}

Conclusion: PI in asymptomatic children was correlated with anaemia and chronic malnutrition and was thus a harmful condition in the study population. Malaria control initiatives should not only focus on treatment of symptomatic infections but also take into consideration asymptomatic but infected children.

Keywords: Plasmodium falciparum, Asymptomatic infection, Anaemia, Nutrition, Children under five, Democratic Republic of Congo

\footnotetext{
* Correspondence: vmaketa@yahoo.fr

'Department of Tropical Medicine, University of Kinshasa, Kinshasa,

Democratic Republic of Congo

${ }^{2}$ International Health Unit, Faculty of Medicine, University of Antwerp,

Antwerp, Belgium

Full list of author information is available at the end of the article
} 


\section{Background}

Globally, according to the World Health Organization (WHO), malaria remains a major public health problem, affecting half the world's population. There were an estimated 207 million episodes of malaria in 2012, of which approximately $81 \%$ occurred in the African region. The estimated number of deaths due to malaria was 627,000 in 2012, of which $90 \%$ were in Africa [1]. However, the real contribution may be higher due to the indirect morbidity rate through other infections, especially in vulnerable groups such as pregnant women and children under the age of five [2-7].

Malaria is preventable and treatable when recommended interventions are properly implemented. Effective preventive measures are: (i) intermittent preventive treatment for pregnant women (ii) indoor insecticide residual spraying and, (iii) the use of bed nets. These preventive measures may be more cost-efficient when combined with systematic screening and treatment of asymptomatic individuals in high-transmission settings [8]. In symptomatic individuals, early diagnosis based on microscopy or rapid diagnostic test and an efficacious treatment are necessary. In addition, all suspected cases of symptomatic Plasmodium infection (PI) should be biologically confirmed prior to treatment [9-14]. Thus, by definition, diagnosis and treatment are focused on symptomatic individuals while asymptomatic ones also play a role in the sustainability of the transmission, acting as a reservoir for the disease [15-19]. Furthermore, asymptomatic PI may have an impact on the morbidity of the disease in terms of anaemia, nutritional status and even cognitive development of children $[2,4-7,20,21]$.

According to the health demographic survey carried out in the Democratic Republic of Congo (DRC) in 2007, almost two-thirds of anaemia cases and up to $85 \%$ of blood transfusions were likely due to episodes of SPI [22]. Plasmodium parasites mainly cause anaemia through hyperhaemolysis of red blood cells and the decrease in erythropoiesis operated through several pathways [23-31]. If the mechanisms of anaemia during PI are well documented, the relationship between PI and malnutrition still needs to be clarified [32]. Some authors suggest that malnutrition may lead to an exacerbation of morbidity or an increasing susceptibility to PI [33-36] while others report a protector effect of malnutrition on PI $[37,38]$.

This paper aims to assess asymptomatic PI prevalence in the vulnerable group of children under the age of five living in malaria-endemic areas and to explore its relationship with morbidity factors such as anaemia and malnutrition status.

\section{Methods}

\section{Study area}

Kinshasa, capital of the DRC, has a surface of 13,195 sq $\mathrm{km}$ and more than eight million inhabitants [39]. The level of malaria transmission is high and perennial. The climate is tropical with two seasons, a rainy season of eight months and a dry season. Kinshasa is divided into six health districts: Nsele, Ndjili, Kalamu, Funa, Lukunga, and Gombe. Each district is further divided into health zones $(\mathrm{HZs})$, the operational level of the health system in DRC, which are further divided into health areas (HAs). The total number of $\mathrm{HZs}$ in Kinshasa is 35 and the number of HAs is 384 [39]. This study was held to have complementary prevalence data on asymptomatic malaria as a Phase IIIb clinical trial was ongoing in the HZ of Mont Ngafula1 [40].

\section{Study design and study population}

The household survey was conducted from April to September 2012 during the dry season. Two HAs, Kindele and Cité Pumbu, were randomly selected from the 16 HAs of Mont Ngafula1 using the RAND function of Microsoft Excel 2007 software. Random selection of households was based on a systematic sampling interval $\mathrm{k}$, determined by dividing the number of households in the neighbourhood (obtained from the Civil Registry), by the number of neighbourhoods. The first household was randomly selected following the expanded programme on immunization (EPI) vaccine coverage survey method [41] and by considering the neighbourhood's civil administration office as the central point of the neighbourhood. Asymptomatic children under the age of five were the targeted population. Questionnaires addressed to children's the parents/guardians were used to collect information on demographic data and predictors of PI.

\section{Sample collection and laboratory analysis}

To assess the prevalence of PI, blood for thick/thin smears and malaria rapid diagnostic test (RDT) were collected from the same finger prick. But this paper only report prevalence assessed by blood smears, results related to malaria RDT are reported elsewhere [42]. Blood smears were prepared on the same slide bearing a patient's identification code. Slides were horizontally airdried in a slide tray and stored in boxes. At the end of the day, blood slides were stained with $10 \%$ Giemsa, but the thin smears were previously fixed with pure methanol. Blood slides were read by experienced laboratory technicians at the Parasitology Laboratory, Kinshasa University. The parasite density (PD) was calculated by counting the number of asexual parasites per 200 leukocytes in the thick blood film. A laboratory technician counted 500 leukocytes before considering a slide as negative. When thick films were positive, thin films were read for species determination. Based on an assumed $8,000 / \mu \mathrm{l}$ white blood cells in children [43], the $\mathrm{PD} / \mu \mathrm{l}$ was calculated using the following formula: 


$$
\text { Parasites } / \mu l(P / \mu l)=\frac{(\text { Number of parasites counted } x \text { 8,000) }}{\text { Number of leukocytes counted }}
$$

Haemoglobin concentration was measured in the laboratory using the Hemocontrol ${ }^{\triangleright}$ device (EKF Diagnostics, Germany) with venous blood collected in the field and stored in vacutainer tubes containing EDTA. Anaemia was classified as mild, moderate and severe when haemoglobin concentrations were respectively 10.9$10.0 \mathrm{~g} / \mathrm{dl}, 9.0-7.0 \mathrm{~g} / \mathrm{dl}$ and $<7 \mathrm{~g} / \mathrm{dl}$ [44].

\section{Nutritional status}

Height was measured to determine the height for age $\mathrm{z}$ score (HAZ) according to the WHO growth standard references for children from zero to five years [45]. A HAZ score $\leq-2$ standard deviation (SD) and $\leq-3$ SD were defined as stunting or moderate chronic malnutrition and severe chronic malnutrition, respectively. The mid upper arm circumference (MUAC) was measured to assess the MUAC z-score according to the WHO growth standard references for children from zero to five years [46]. MUAC score $\leq-2 \mathrm{SD}$ and $\leq-3 \mathrm{SD}$ were defined as moderate and severe acute malnutrition respectively.

\section{Asymptomatic PI}

Asymptomatic PI was assessed as the presence $P$. falciparum trophozoite on a blood smear and, the absence of temperature above $37.5{ }^{\circ} \mathrm{C}$ (axillary) or history of fever in the past 48 hours.

\section{Data analysis}

Data were double-entered and validated in Epi info version 3.5.1. software and analysed using Stata version 11 (Stata Corp, College Station, Texas, USA). For the different statistical tests the level of significance was set at $5 \%$. Progressive stepwise pr (0.10) backward pe (0.05) models were used to assess the predictor factors for the variables of interest.

\section{Ethical consideration}

Ethical clearance was obtained by the Ethics Committee of the Public Health School of the University of Kinshasa. Written informed consent was collected from the parents or legal guardians prior to inclusion of the children. Thumb-printed consents were collected in the presence of an independent witness whenever the parents or legal guardians were illiterate. All children with a positive malaria RDT and/or blood smear were supplied with anti-malarial drugs as recommended by DRC national guidelines.

\section{Results}

A total of 700 children under the age of five were included, 317 (45.3\%) girls and 383 (54.7\%) boys. The median age was 43.1 months (IQR: 28.0-54.6). The majority of the children (93.9\%) were living in a household without screening on the windows. Moreover, 257 (36.7\%) children were living in household that owned at least one insecticide-treated net (ITN) 162 (23.1\%) slept under the ITN the night prior to data collection. Reasons given for the non-use of ITN by the parents were the heat $(9.1 \%)$, children did not tolerate sleeping under the ITN $(2.3 \%)$, the parents forgot to install the ITN (4.0\%). but in the majority of the cases $(84.6 \%)$, the parents gave no explanation. There was no significant difference regarding the proportion of ITN utilization within age group categories or HAs. Almost half of the children (49.4\%) were living in a compound with more than eleven individuals and most of the households (55.9\%) were composed of more than ten persons. The majority of parents were married or in couple $(81.3 \%)$ with highest achieved educational level of secondary school (71.9\%), and their professional occupations were diverse (Additional file 1).

The mean prevalence of PI in the two HAs was $23.1 \%$ (95\% CI: 20.1-26.4), among them, 4.6\% (95\% CI: 3.0-6.1), 6.3\% (95\% CI: 4.4-8.0), 12.2\% (95\% CI: 9.8-14.7), respectively, had a $\mathrm{PD}<1,000 / \mu \mathrm{l}, \mathrm{PD}$ ranging from $1,000 / \mu \mathrm{l}$ to $2,000 / \mu \mathrm{l}$ and $\mathrm{PD}>2,000 / \mu \mathrm{l}$. The median PD was $2,357 / \mu \mathrm{l}$ (IQR: 1,120-6,868/ $\mu$ l, range: $32-137,600)$. Within the HAs, the prevalence of PI was 30.9\% (95\% CI: 26.5-35.9) and $14.3 \%$ (95\% CI: 10.5-18.1), respectively, in Cité Pumbu and Kindele with OR 2.7 ( $\mathrm{p}<0.001$ ). In Cité Pumbu, the median PD was 2,000/ $\mu$ l (IQR: 1,121-6,400/ $\mu \mathrm{l}$; range: $32-137,600)$ while median $\mathrm{PD}$ was $3,360 / \mu \mathrm{l}$ (IQR: 1,120-10,849/ $\mu$; range: 48-49,098) in Kindele. There was a significantly lower proportion of children having PI in those sleeping under an $\operatorname{ITN}(\mathrm{p}=0.01)$ compared to those who did not slept under an ITN when the PD was above $2,000 / \mu$ l (Table 1 ).

Species identification revealed that $P$. falciparum was found in all positive smears, and mixed with $P$. malariae in $4 \%$ (29 slides) of cases. Among the samples, there were $1.6 \%$ (11 slides) which showed solely $P$. falciparum gametocytes, but they were considered a negative microscopic outcome.

The overall prevalence of anaemia in the two HAs was 51.1\% (95\% CI: 47.4-54.9) with 36.8\% (95\% CI: 33.340.4), 9.9\% (95\% CI: 7.6-12.1) and 4.4\% (95\% CI: 3.0-6.0) having, respectively, mild, moderate and severe anaemia. The median haemoglobin level in the study population was $10.9 \mathrm{~g} / \mathrm{dl}$ (IQR: 9.8-11.9; range: 4.0-19.0). In Cité Pumbu and Kindele, the prevalence of anaemia was, respectively, 61.6\% (95\% CI: 56.6-66.5) and 39.3\% (95\% CI: 34.0-44.6), OR: 2.5, p <0.001. Median haemoglobin levels were $10.6 \mathrm{~g} / \mathrm{dl}$ (IQR: 9.6-11.5, range: 4.0-19.0) and $11.5 \mathrm{~g} / \mathrm{dl}$ (IQR: 10.4-12.2; range: 4.5-17.2), respectively, in Cité Pumbu and Kindele. 
Table 1 L Proportion of PI according to utilization of bed net in two health areas in Mont Ngafula1, Kinshasa, DRC, 2012

\begin{tabular}{|c|c|c|c|c|c|}
\hline Sleep under ITN & $\begin{array}{l}\text { Uninfected \% } \\
(95 \% \mathrm{Cl})\end{array}$ & $\begin{array}{l}\text { Overall PI \% } \\
(95 \% \mathrm{Cl})\end{array}$ & $\begin{array}{l}\mathrm{PI}<1000 \mathrm{p} / \mu \mathrm{l} \% \\
(95 \% \mathrm{Cl})\end{array}$ & $\begin{array}{l}\mathrm{PI} 1000-2000 \mathrm{p} / \mu \mathrm{l} \% \\
(95 \% \mathrm{Cl})\end{array}$ & $\begin{array}{l}\mathrm{PI}>2000 \mathrm{p} / \mu \mathrm{l} \% \\
(95 \% \mathrm{Cl})\end{array}$ \\
\hline No $n=538$ & 74.5 (70.8-78.2) & $25.5(21.7-29.2)$ & $4.3(2.6-6.0)$ & $6.9(4.7-9.0)$ & $14.3(11.3-17.3)$ \\
\hline Yes $n=162$ & 84.5 (79.0-90.2) & $15.5(9.8-21.0)$ & $5.6(2.0-9.0)$ & $4.3(1.1-7.5)$ & $5.6(2.0-9.0)$ \\
\hline
\end{tabular}

The prevalence of acute malnutrition was $14.7 \%(95 \%$ CI: $12.1-17.3$ ) with $5.1 \%$ (95\% CI: 3.5-6.8) and $9.6 \%$ (95\% CI: 7.4-11.8) of children having, respectively, moderate and severe acute malnutrition. The HA of Kindele had a larger proportion of acute malnutrition (27.4\%; 95\% CI: 22.6-32.3) compared to Cité Pumbu (3.5\%; 95\% CI: 1.6-5.4) OR:10.4, p <0.001. The prevalence of chronic malnutrition was $19.6 \%$ (95\% CI: 16.622.5 ) with $11.6 \%$ (95\% CI: 9.2-13.9) and 1.0\% (95\% CI: 6.0-10.0) of children having, respectively, moderate and severe chronic malnutrition. The HA of Cité Pumbu had a larger proportion of chronic malnutrition of 32\% (95\% CI: 27.5-37.0) compared to 5.1\% (95\% CI: 2.8-7.6) in Kindele, OR: 8.7;p <0.0001.

\section{Predictors of PI}

Age above 12 months, presence of anaemia, chronic malnutrition, having a single parent/guardian, head of household with a lower education, and the non-use of ITNs were predictor factors for PI in the overall population (Table 2). In Cité Pumbu the presence of anaemia, the presence of chronic malnutrition and a lower education of the household head were correlated with PI, while in Kindele, anaemia was the sole correlate (Table 2).

\section{Predictors of anaemia and nutritional status}

In the overall population, children older than 12 months, having PI and having a non-employed household head were significantly more at risk of anaemia (Table 3). Figure 1 shows that uninfected children have a significantly higher haemoglobin level in general, regardless of age, indicating that children with parasitaeamia had higher risk of anaemia (OR: 3.6, p =0.001). Moreover, within the infected children group, an inverse relationship between PD and haemoglobin level was observed $\left(\beta=-5 * 10^{-5}, \mathrm{p}<0.001\right)$ (Figure 2).

In the study population, the absence of screening on the windows was shown as a predictor for acute malnutrition while presence of PI and having a non-employed

Table 2 Predictor for PI (progressive stepwise (pr 0.10$)$ backward pe $(0.05)$ model) in asymptomatic children of two health areas of Mont Ngafula1, Kinshasa, DRC, 2012

\begin{tabular}{|c|c|c|c|c|c|c|}
\hline \multirow[b]{2}{*}{ Variables } & \multicolumn{2}{|c|}{ Population $\mathrm{N}=700$} & \multicolumn{2}{|c|}{ Cité Pumbu $n=372$} & \multicolumn{2}{|c|}{ Kindele $n=328$} \\
\hline & $\mathrm{aOR}$ & $p$ value & aOR & $\mathrm{p}$ value & $\overline{O R}$ & $p$ value \\
\hline \multicolumn{7}{|l|}{ Age (Months) } \\
\hline$\leq 12$ & 1 & & 1 & & & \\
\hline$>12$ & 3.8 & 0.01 & 5.1 & 0.003 & & \\
\hline \multicolumn{7}{|l|}{ Anaemia } \\
\hline No & 1 & & 1 & & 1 & \\
\hline Yes & 3.4 & $<0.001$ & 3.4 & $<0.001$ & 2.8 & 0.001 \\
\hline \multicolumn{7}{|l|}{ Chronic malnutrition } \\
\hline No & 1 & & & & & \\
\hline Yes & 1.8 & 0.01 & & & & \\
\hline \multicolumn{7}{|c|}{ Status of the parent/guardians } \\
\hline In couple & 1 & & & & & \\
\hline Single & 1.6 & 0.04 & & & & \\
\hline \multicolumn{7}{|c|}{ Education of the parents/guardians } \\
\hline University & & & 1 & & & \\
\hline Below university level & & & 3.8 & 0.04 & & \\
\hline \multicolumn{7}{|l|}{ Slept under ITN } \\
\hline Yes & 1 & & 1 & & & \\
\hline No & 1.7 & 0.04 & 2.2 & 0.01 & & \\
\hline
\end{tabular}


Table 3 Predictor for anaemia (progressive stepwise (pr 0.10$)$ backward pe $(0.05)$ model) in two health areas of Mont Ngafula1, Kinshasa, DRC, 2012

\begin{tabular}{|c|c|c|c|c|c|c|}
\hline \multirow[b]{2}{*}{ Variables } & \multicolumn{2}{|c|}{ Population $\mathrm{N}=700$} & \multicolumn{2}{|c|}{ Cité Pumbu $n=372$} & \multicolumn{2}{|c|}{ Kindele $\mathbf{n}=328$} \\
\hline & aOR & $\mathrm{p}$ value & $\mathrm{aOR}$ & $\mathrm{p}$ value & $\mathrm{aOR}$ & $p$ value \\
\hline \multicolumn{7}{|l|}{ Age (months) } \\
\hline$>12$ & 1 & & 1 & & & \\
\hline$\leq 12$ & 2.6 & 0.01 & 2.8 & 0.01 & & \\
\hline \multicolumn{7}{|l|}{ PI } \\
\hline No & 1 & & 1 & & 1 & \\
\hline Yes & 3.5 & 0.001 & 3.6 & $<0.001$ & 2.9 & 0.001 \\
\hline \multicolumn{7}{|c|}{ Profession of the household head } \\
\hline Salaried employee & 1 & & 1 & & & \\
\hline Other & 2.0 & 0.001 & 2.2 & 0.078 & & \\
\hline
\end{tabular}

household head were predictors for chronic malnutrition (Table 4).

\section{Discussion}

The prevalence of PI in the two HAs of the HZ of Mont Ngafula I was different between Cité Pumbu and Kindele. Children in Cité Pumbu were almost three times more at risk of having parasitaemia. Therefore the results may not be representative for the whole $\mathrm{HZ}$ because of the high heterogeneity within the HAs. This difference may be explained by microclimatic differences between the two HAs, such as transmission intensity, as in endemic contexts the proportion of children with PI has spatio-temporal variances $[47,48]$. There were $1.6 \%$ of children who carried only gametocytes, this condition can be due to anti-malarial treatment prior to the visit [49-51] although no parent/guardian mentioned it. In the field, report of previous medication by parents is not always effective. For example, a study held in Tanzania detected anti-malarial drugs in the blood of $80 \%$ of screened children under the age of five, despite the fact no parents reported an intake of anti-malarials in the previous 28 days [52]. In the context of this study, as it was stated in the consent form that children with PI would be treated despite the absence of fever, one might assume that parents/guardians preferred to hide information about previous drug intake to ensure their children would benefit from the study medication, as noticed on the clinical trial site (Kalabuanga et al. personal communication).

Children under one year of age were protected from asymptomatic infection. One might assume an intensive use of bed nets in that age group but there was no difference according to the use of ITNs within age groups. In younger children, especially under six months old, the presence of maternal antibodies may decrease the prevalence of PI and therefore of asymptomatic infection $[53,54]$, while in older infants, over six months, when

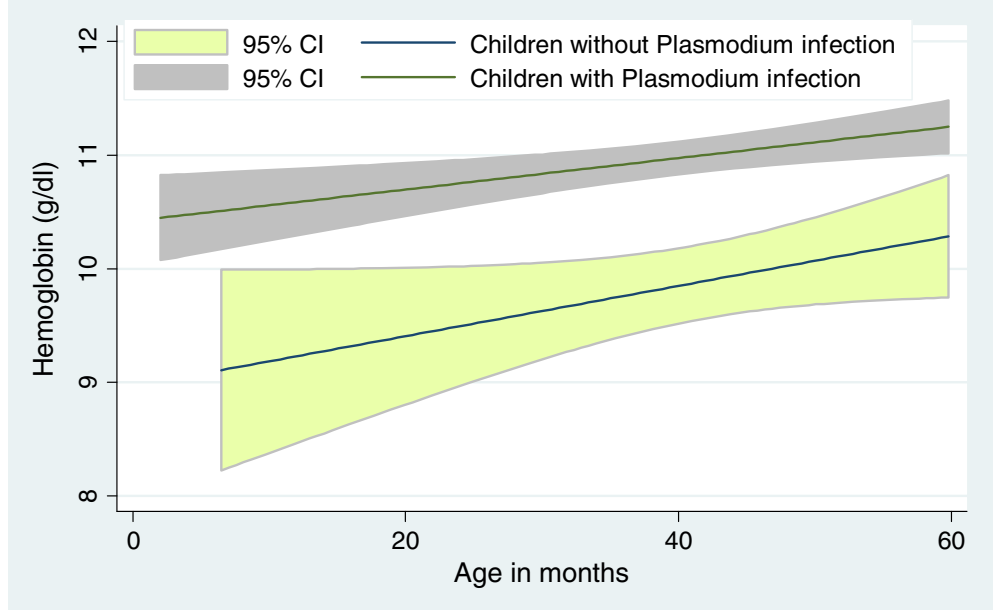

Figure 1 Fitted line plot of haemoglobin concentration $(\mathrm{g} / \mathrm{dl})$ in children (age/month) with or without asymptomatic parasitaemia in two health areas of Mont Ngafula 1, Kinshasa, DR Congo, 2012. 


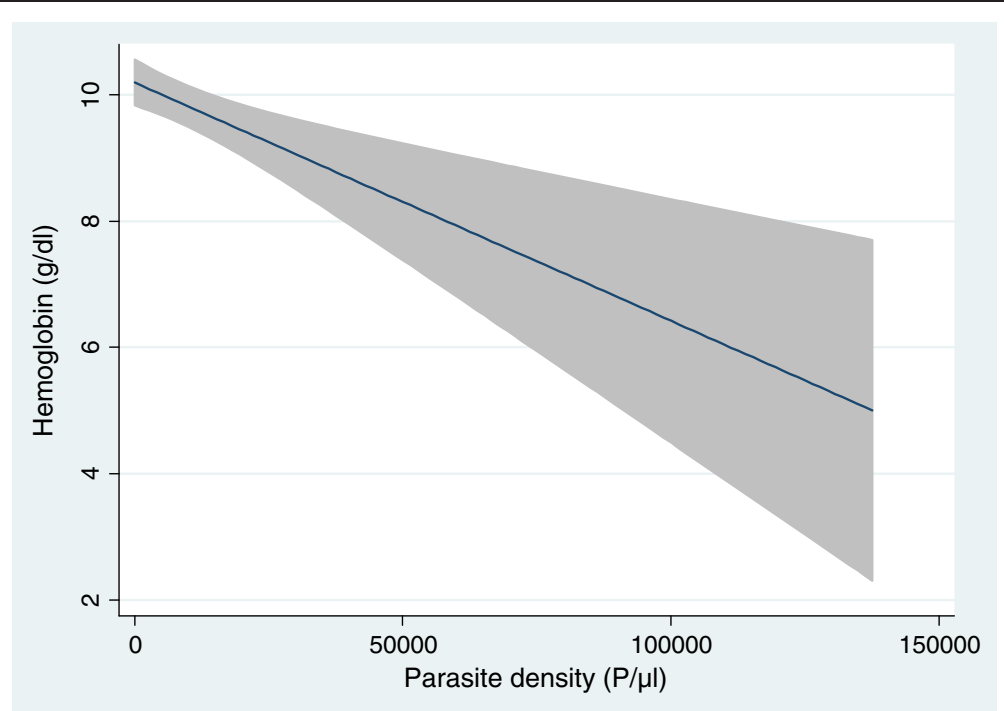

Figure 2 Fitted line plot of haemoglobin concentration $(\mathrm{g} / \mathrm{dl})$ according to the parasite density $(\mathrm{p} / \mu \mathrm{l})$ in children under the age of five in two health areas of Mont Ngafula 1, Kinshasa, DR Congo, 2012 (shaded area is $95 \% \mathrm{Cl}$ ).

maternal protection wanes, asymptomatic infection may be uncommon as the lack of acquired anti-malaria immunity deviates these children immediately to symptomatic or even severe symptomatic malaria episodes, decreasing the prevalence of asymptomatic infection in these infants $[55,56]$.

The use of ITNs reduces the contact between host and vector and as shown in this study, children sleeping under ITNs were significantly less at risk of PI. There is evidence in the literature of the positive impact of their use on reduction of disease [15,57-59], but, paradoxically, the protection of ITNs brings the fear of shifting vulnerability to malaria onto school-aged children: on the one hand, schoolchildren may use ITNs less, and on the other hand, an impaired acquisition of immunity to malaria due to diminished contact with Plasmodium at younger age [58,60-64]. ITNs were efficient in preventing parasitaemia only when $\mathrm{PD}$ was $\geq 2,000 / \mu$ l, which might explain the decrease of mortality due to malaria by the use of ITNs [65], as patients with symptomatic PI tend to have a higher PD than asymptomatic subjects [66]. However, the finding that ITNs did not affect the overall proportion of asymptomatic children with PI is intriguing. A low PD might be considered a benefit since it could act, similarly to the use of intermittent preventive treatment, as a blood stage vaccine $[67,68]$. Unfortunately, it can be argued that PI alone, whatever the PD is, is a harmful condition because of its impact at community level on the sustainability of transmission $[2,8]$. Moreover, a longitudinal study performed in Uganda showed that asymptomatic children with PI were almost five times more at risk to develop a clinical episode of malaria within 30 days than children without parasitaemia [69]. In the study population, children with PI had significantly lower haemoglobin levels. Analysis revealed

Table 4 Predictor for acute and chronic malnutrition (progressive stepwise (pr 0.10$)$ backward pe (0.05) model) in health zone of Mont Ngafula1, Kinshasa, DRC, 2012

\begin{tabular}{|c|c|c|c|c|}
\hline \multirow[t]{2}{*}{ Variables } & \multicolumn{2}{|c|}{ Acute malnutrition (MUAC) } & \multicolumn{2}{|c|}{ Chronic malnutrition (HAZ-score) } \\
\hline & aOR & $p$ value & aOR & $p$ value \\
\hline \multicolumn{5}{|l|}{$\mathrm{Pl}$} \\
\hline No & - & - & 1 & \\
\hline Yes & - & - & 1.9 & 0.004 \\
\hline \multicolumn{5}{|c|}{ Profession of the household head } \\
\hline Salaried employee & - & - & 1 & \\
\hline Other & - & - & 2.2 & 0.02 \\
\hline \multicolumn{5}{|c|}{ Presence of screening on windows } \\
\hline Yes & 1 & & - & - \\
\hline No & 2.4 & 0.03 & - & - \\
\hline
\end{tabular}


that PD and haemoglobin levels were inversely correlated with children more likely to suffer from severe anaemia when they are highly infected. However, in a tropical context, with interaction between many factors, anaemia cannot be said to be a consequence of PI alone [70] but, in endemic settings, an assumption could be that anaemia might be related to former PI episodes. In face of such evidence it is clear that asymptomatic PI may be a harmful condition due to its direct and public health impact on haemoglobin levels, particularly in the vulnerable group of children under five [71-74]. In the study population, chronic malnutrition and anaemia were all correlated, nevertheless, the causality chain, cannot be determined through a cross-sectional design. Longitudinal studies are needed to answer this question. A limitation of this study is a possible underestimation of the prevalence of PI because of its assessment with a BS instead of PCR [75].

The prevalence of acute and chronic malnutrition were 15 and $20 \%$, respectively, which is higher than the prevalence previously reported in Kinshasa (4\%) in the same age group [22], but this may be due to ecological effect as this study included only two HAs of a city that has 384 HAs in total. As in an endemic setting, asymptomatic PI although can be considered an intermittent chronic condition; longitudinal studies are also needed to assess its the relation with nutritional status. The high heterogeneity within the two HAs in terms of nutritional status may be related to different socio-economical patterns in the two HAs, but, again, other studies are needed to explore these issues.

\section{Conclusion}

PI although asymptomatic was correlated with anaemia and chronic malnutrition and is thus a harmful condition in the children under the age of five years. Thus, malaria control initiatives should also target asymptomatic PI to reduce malaria-associated morbidity.

\section{Additional file}

Additional file 1: Table S1. Demographic characteristic and median parasite density of Plasmodium falciparum of asymptomatic children in 2 health areas of Mont Ngafula1, Kinshasa, DRC, 2012.

\section{Authors' contributions}

VM wrote the paper. VM, JPVg and PL designed the protocol, VM, HM and JZ collected data in the field, VM, RIL and JPVg performed statistical analysis. All authors read and approved the submitted manuscript.

\section{Acknowledgements}

We thank the study participants and the study team: Henry Kabongo, Olga Kabedi, Eugene Paluku. This study was co-funded by VLIR-UOS and SACIDS.

\section{Author details}

${ }^{1}$ Department of Tropical Medicine, University of Kinshasa, Kinshasa, Democratic Republic of Congo. ${ }^{2}$ International Health Unit, Faculty of Medicine, University of Antwerp, Antwerp, Belgium. ${ }^{3}$ Santé Rurale (SANRU), Kinshasa, Democratic Republic of Congo.

Received: 3 December 2014 Accepted: 30 January 2015

Published online: 18 February 2015

\section{References}

1. WHO. World malaria report 2013. Geneva: World Health Organization; 2013.

2. Douamba Z, Bisseye C, Djigma FW, Compaore TR, Bazie VJ, Pietra V, et al. Asymptomatic malaria correlates with anaemia in pregnant women at Ouagadougou, Burkina Faso. J Biomed Biotechnol. 2012;2012:198317.

3. Greenwood BM, Bojang K, Whitty CJ, Targett GA. Malaria. Lancet. 2005;365:1487-98.

4. Isah AY, Amanabo MA, Ekele BA. Prevalence of malaria parasitemia amongst asymptomatic pregnant women attending a Nigerian teaching hospital. Ann Afr Med. 2011;10:171-4.

5. McGregor IA. Malaria: nutritional implications. Rev Infect Dis. 1982;4:798-804.

6. Noland GS, Ayodo G, Abuya J, Hodges JS, Rolfes MA, John CC. Decreased prevalence of anemia in highland areas of low malaria transmission after a 1-year interruption of transmission. Clin Infect Dis. 2012;54:178-84.

7. Sharp PT, Harvey P. Malaria and growth stunting in young children of the highlands of Papua New Guinea. P N G Med J. 1980;23:132-40.

8. Crowell V, Briet OJ, Hardy D, Chitnis N, Maire N, Di PA, et al. Modelling the cost-effectiveness of mass screening and treatment for reducing Plasmodium falciparum malaria burden. Malar J. 2013;12:4.

9. Bisoffi Z, Van den Ende J. Costs of treating malaria according to test results. BMJ. 2008;336:168-9

10. Bisoffi Z, Gobbi F, Angheben A, Van den Ende J. The role of rapid diagnostic tests in managing malaria. PLoS Med. 2009;6:e1000063.

11. D'Acremont V, Lengeler C, Mshinda H, Mtasiwa D, Tanner M, Genton B. Time to move from presumptive malaria treatment to laboratory-confirmed diagnosis and treatment in African children with fever. PLoS Med. 2009:6:e252.

12. English M, Reyburn H, Goodman C, Snow RW. Abandoning presumptive antimalarial treatment for febrile children aged less than five years-a case of running before we can walk? PLoS Med. 2009;6:e1000015

13. Gerstl S, Dunkley S, Mukhtar A, De SM, Baker S, Maikere J. Assessment of two malaria rapid diagnostic tests in children under five years of age, with follow-up of false-positive pLDH test results, in a hyperendemic falciparum malaria area, Sierra Leone. Malar J. 2010;9:28.

14. WHO. Guidelines for the treatment of malaria. Geneva: World Health Organization; 2010

15. Doumbia SO, Ndiaye D, Koita OA, Diakite M, Nwakanma D, Coulibaly M, et al. Improving malaria control in West Africa: interruption of transmission as a paradigm shift. Acta Trop. 2012;121:175-83.

16. Dunyo S, Milligan P, Edwards T, Sutherland C, Targett G, Pinder M. Gametocytaemia after drug treatment of asymptomatic Plasmodium falciparum. PLoS Clin Trials. 2006:1:e20.

17. Griffin JT, Hollingsworth TD, Okell LC, Churcher TS, White M, Hinsley W, et al Reducing Plasmodium falciparum malaria transmission in Africa: a modelbased evaluation of intervention strategies. PLoS Med. 2010;7:e1000324.

18. Kern SE, Tiono AB, Makanga M, Gbadoé AD, Premji Z, Gaye O, et al. Community screening and treatment of asymptomatic carriers of Plasmodium falciparum with artemether-lumefantrine to reduce malaria disease burden: a modelling and simulation analysis. Malar J. 2011;10:210.

19. Vafa M, Troye-Blomberg M, Anchang J, Garcia A, Migot-Nabias F. Multiplicity of Plasmodium falciparum infection in asymptomatic children in Senegal: relation to transmission, age and erythrocyte variants. Malar J. 2008;7:17. 
20. Caulfield LE, Richard SA, Black RE. Undernutrition as an underlying cause of malaria morbidity and mortality in children less than five years old. Am J Trop Med Hyg. 2004;71(2 Suppl):55-63.

21. Jeremiah ZA, Uko EK. Childhood asymptomatic malaria and nutritional status among Port Harcourt children. East Afr J Public Health. 2007:4:55-8.

22. Ministère du Plan avec la collaboration du Ministère de la Santé: Enquête Démographique de Santé RDC 2007. Kinshasa: République Démocratique du Congo; 2008.

23. Angus BJ, Chotivanich $K$, Udomsangpetch $R$, White $N J$. In vivo removal of malaria parasites from red blood cells without their destruction in acute falciparum malaria. Blood. 1997;90:2037-40.

24. Clark IA, Chaudhri G. Tumour necrosis factor may contribute to the anaemia of malaria by causing dyserythropoiesis and erythrophagocytosis. $\mathrm{Br} \mathrm{J}$ Haematol. 1988;70:99-103.

25. Davis TM, Krishna S, Looareesuwan S, Supanaranond W, Pukrittayakamee S, Attatamsoonthorn $\mathrm{K}$, et al. Erythrocyte sequestration and anemia in severe falciparum malaria. Analysis of acute changes in venous hematocrit using a simple mathematical model. J Clin Invest. 1990;86:793-800.

26. Dondorp AM, Angus BJ, Chotivanich K, Silamut K, Ruangveerayuth R, Hardeman MR, et al. Red blood cell deformability as a predictor of anemia in severe falciparum malaria. Am J Trop Med Hyg. 1999;60:733-7.

27. el Hassan AM, Saeed AM, Fandrey J, Jelkmann W. Decreased erythropoietin response in Plasmodium falciparum malaria-associated anaemia. Eur J Haematol. 1997;59:299-304.

28. Hotez PJ, Fenwick A. Schistosomiasis in Africa: an emerging tragedy in our new global health decade. PLoS Negl Trop Dis. 2009;3:e485.

29. Menendez C, Kahigwa E, Hirt R, Vounatsou P, Aponte JJ, Font F, et al. Randomised placebo-controlled trial of iron supplementation and malaria chemoprophylaxis for prevention of severe anaemia and malaria in Tanzanian infants. Lancet. 1997;350:844-50.

30. Phillips RE, Pasvol G. Anaemia of Plasmodium falciparum malaria. Baillieres Clin Haematol. 1992:5:315-30.

31. Van den Ende J. Recurrence of blackwater fever: triggering of relapses by different antimalarials. Trop Med Int Health. 1998;3:632-9.

32. Crookston BT, Alder SC, Boakye I, Merrill RM, Amuasi JH, Porucznik CA, et al. Exploring the relationship between chronic undernutrition and asymptomatic malaria in Ghanaian children. Malar J. 2010;9:39.

33. Deen $\mathrm{L}$, Walraven $\mathrm{GE}$, von Seidlein L. Increased risk for malaria in chronically malnourished children under 5 years of age in rural Gambia. J Trop Pediatr. 2002;48:78-83.

34. Ehrhardt S, Burchard GD, Mantel C, Cramer JP, Kaiser S, Kubo M, et al. Malaria, anemia, and malnutrition in african children-defining intervention priorities. J Infect Dis. 2006;194:108-14.

35. Shankar AH. Nutritional modulation of malaria morbidity and mortality. J Infect Dis. 2000;182 Suppl 1:S37-53.

36. Takakura M, Uza M, Sasaki Y, Nagahama N, Phommpida S, Bounyadeth S, et al. The relationship between anthropometric indicators of nutritional status and malaria infection among youths in Khammouane Province, Lao PDR. Southeast Asian J Trop Med Public Health. 2001;32:262-7.

37. Goyal SC. Protein energy malnutrition and cerebral malaria. J Trop Pediatr. 1991;37:143-4

38. Hendrickse RG, Hasan AH, Olumide LO, Akinkunmi A. Malaria in early childhood. An investigation of five hundred seriously ill children in whom a "clinical" diagnosis of malaria was made on admission to the children's emergency room at University College Hospital, Ibadan. Ann Trop Med Parasitol. 1971;65:1-20.

39. Ministère de la Sante Publique de la santé. Secrétariat général de la santé Kinshasa.DRC: Rapport 2009 de l'Inspection Provinciale de Kinshasa. Kinshasa: République Démocratique du Congo; 2010.

40. Muhindo MH, Nabasumba C, Tinto H, D'Alessandro U, Grobusch MP, Lutumba $P$, et al. Impact of retreatment with an artemisinin-based combination on malaria incidence and its potential selection of resistant strains: study protocol for a randomized controlled clinical trial. Trials. 2013;14:307.

41. Bennett S, Woods T, Liyanage WM, Smith DL. A simplified general method for cluster-sample surveys of health in developing countries. World Health Stat Q. 1991:44:98-106

42. Nombe G, Maketa V, Mavoko HM, da Luz RI, Lutumba P, Van Geertruyden JP. Performance of HRP2-based rapid test in children attending the health centre compared to asymptomatic children in the community. Malar J. 2014;13:308.

43. WHO. Basic malaria microscopy: Part I Learner' s guide, Part II tutor's guide. Geneva: World Health Organization; 1991.
44. WHO. Haemoglobin concentrations for the diagnosis of anaemia and assessment of severity. Vitamin and Mineral Nutrition Information System. Geneva: World Health Organization; 2011.

45. Multicentre Growth Reference Study Group WHO. WHO Child Growth Standards: Length/height-for-age, weight-for-age, weight-for-length, weight-for-height and body mass index-for-age: Methods and development. Geneva: World Health Organization; 2006.

46. WHO Multicentre Growth Reference Study Group. WHO Child Growth Standards: Head circumference-for-age, arm circumference-for-age, triceps skinfold-for-age and subscapular skinfold-for-age: Methods and development. Geneva: World Health Organization; 2007.

47. Baliraine FN, Afrane YA, Amenya DA, Bonizzoni M, Menge DM, Zhou G, et al. High prevalence of asymptomatic Plasmodium falciparum infections in a highland area of western Kenya: a cohort study. J Infect Dis. 2009;200:66-74.

48. Ogutu B, Tiono AB, Makanga M, Premji Z, Gbadoe AD, Ubben D, et al. Treatment of asymptomatic carriers with artemether-lumefantrine: an opportunity to reduce the burden of malaria? Malar J. 2010;9:30.

49. Beavogui AH, Djimde AA, Gregson A, Toure AM, Dao A, Coulibaly B, et al. Low infectivity of Plasmodium falciparum gametocytes to Anopheles gambiae following treatment with sulfadoxine-pyrimethamine in Mali. Int J Parasitol. 2010:40:1213-20.

50. Bousema T, Okell L, Shekalaghe S, Griffin JT, Omar S, Sawa P, et al. Revisiting the circulation time of Plasmodium falciparum gametocytes: molecular detection methods to estimate the duration of gametocyte carriage and the effect of gametocytocidal drugs. Malar J. 2010;9:136.

51. McGready R, White NJ, Nosten F. Parasitological efficacy of antimalarials in the treatment and prevention of falciparum malaria in pregnancy 1998 to 2009: a systematic review. BJOG. 2011;118:123-35.

52. Hodel EM, Kabanywanyi AM, Malila A, Zanolari B, Mercier T, Beck HP, et al. Residual antimalarials in malaria patients from Tanzania-implications on drug efficacy assessment and spread of parasite resistance. PLoS One. 2009;4:e8184.

53. Amaratunga C, Lopera-Mesa TM, Brittain NJ, Cholera R, Arie T, Fujioka H, et al. A role for fetal hemoglobin and maternal immune lgG in infant resistance to Plasmodium falciparum malaria. PLoS One. 2011;6:e14798.

54. Billig EM, McQueen PG, McKenzie FE. Foetal haemoglobin and the dynamics of paediatric malaria. Malar J. 2012;11:396.

55. Jagannathan P, Muhindo MK, Kakuru A, Arinaitwe E, Greenhouse B, Tappero $J$, et al. Increasing incidence of malaria in children despite insecticidetreated bed nets and prompt anti-malarial therapy in Tororo, Uganda. Malar J. 2012;11:435

56. Abdullah S, Adazu K, Masanja H, Diallo D, Hodgson A, Ilboudo-Sanogo E, et al. Patterns of age-specific mortality in children in endemic areas of subSaharan Africa. Am J Trop Med Hyg. 2007;77(Suppl):99-105.

57. Ghani AC, Sutherland CJ, Riley EM, Drakeley CJ, Griffin JT, Gosling RD, et al. Loss of population levels of immunity to malaria as a result of exposurereducing interventions: consequences for interpretation of disease trends. PLoS One. 2009;4:e4383.

58. Laishram DD, Sutton PL, Nanda N, Sharma VL, Sobti RC, Carlton JM, et al. The complexities of malaria disease manifestations with a focus on asymptomatic malaria. Malar J. 2012;11:29.

59. Tiono AB, Guelbeogo MW, Sagnon NF, Nebie I, Sirima SB, Mukhopadhyay A, et al. Dynamics of malaria transmission and susceptibility to clinical malaria episodes following treatment of Plasmodium falciparum asymptomatic carriers: results of a cluster-randomized study of community-wide screening and treatment, and a parallel entomology study. BMC Infect Dis. 2013;13:535.

60. Askjaer N, Maxwell C, Chambo W, Staalsoe T, Nielsen M, Hviid L, et al. Insecticide-treated bed nets reduce plasma antibody levels and limit the repertoire of antibodies to Plasmodium falciparum variant surface antigens. Clin Diagn Lab Immunol. 2001;8:1289-91.

61. Bull PC, Lowe BS, Kaleli N, Njuga F, Kortok M, Ross A, et al. Plasmodium falciparum infections are associated with agglutinating antibodies to parasite-infected erythrocyte surface antigens among healthy Kenyan children. J Infect Dis. 2002;185:1688-91.

62. Cavanagh DR, Elhassan IM, Roper C, Robinson VJ, Giha H, Holder AA, et al. A longitudinal study of type-specific antibody responses to Plasmodium falciparum merozoite surface protein-1 in an area of unstable malaria in Sudan. J Immunol. 1998;161:347-59.

63. Kobbe R, Hogan B, Adjei S, Klein P, Kreuels B, Loag W, et al. Follow-up survey of children who received sulfadoxine-pyrimethamine for intermittent preventive antimalarial treatment in infants. J Infect Dis. 2011;203:556-60. 
64. Rogerson SJ, Wijesinghe RS, Meshnick SR. Host immunity as a determinant of treatment outcome in Plasmodium falciparum malaria. Lancet Infect Dis. 2010;10:51-9.

65. D'Alessandro U, Olaleye BO, McGuire W, Langerock P, Bennett S, Aikins MK, et al. Mortality and morbidity from malaria in Gambian children after introduction of an impregnated bednet programme. Lancet. 1995;345:479-83.

66. Koram KA, Molyneux ME. When is "malaria" malaria? The different burdens of malaria infection, malaria disease, and malaria-like illnesses. Am J Trop Med Hyg. 2007;77 Suppl 6:1-5.

67. Greenwood B. The use of anti-malarial drugs to prevent malaria in the population of malaria-endemic areas. Am J Trop Med Hyg. 2004;70:1-7.

68. Sutherland CJ, Drakeley CJ, Schellenberg D. How is childhood development of immunity to Plasmodium falciparum enhanced by certain antimalarial interventions? Malar J. 2007;6:161

69. Njama-Meya D, Kamya MR, Dorsey G. Asymptomatic parasitaemia as a risk factor for symptomatic malaria in a cohort of Ugandan children. Trop Med Int Health. 2004;9:862-8.

70. Hotez PJ, Molyneux DH. Tropical anemia: one of Africa's great killers and a rationale for linking malaria and neglected tropical disease control to achieve a common goal. PLoS Negl Trop Dis. 2008;2:e270.

71. Stauffer W, Fischer PR. Diagnosis and treatment of malaria in children. Clin Infect Dis. 2003;37:1340-8.

72. Jaenisch T, Sullivan DJ, Dutta A, Deb S, Ramsan M, Othman MK, et al. Malaria incidence and prevalence on Pemba island before the onset of the successful control intervention on the Zanzibar archipelago. Malar J. 2010;9:32.

73. Chizema-Kawesha E, Miller JM, Steketee RW, Mukonka VM, Mukuka C, Mohamed AD, et al. Scaling up malaria control in Zambia: progress and impact 2005-2008. Am J Trop Med Hyg. 2010;83:480-8.

74. Matangila JR, Lufuluabo J, Ibalanky AL, Inocencio da Luz RA, Lutumba P, Van Geertruyden JP. Asymptomatic Plasmodium falciparum infection is associated with anaemia in pregnancy and can be more cost-effectively detected by rapid diagnostic test than by microscopy in Kinshasa, Democratic Republic of the Congo. Malar J. 2014;13:132.

75. Bottius E, Guanzirolli A, Trape JF, Rogier C, Konate L, Druilhe P. Malaria: even more chronic in nature than previously thought; evidence for subpatent parasitaemia detectable by the polymerase chain reaction. Trans $\mathrm{R}$ Soc Trop Med Hyg. 1996;90:15-9.

\section{Submit your next manuscript to BioMed Central and take full advantage of:}

- Convenient online submission

- Thorough peer review

- No space constraints or color figure charges

- Immediate publication on acceptance

- Inclusion in PubMed, CAS, Scopus and Google Scholar

- Research which is freely available for redistribution

Submit your manuscript at www.biomedcentral.com/submit 